\title{
Hydration of Heavy Alkaline-Earth Cations Studied by Molecular Dynamics Simulations and X-ray Absorption Spectroscopy
}

\author{
Rafael R. Pappalardo, Daniel Z. Caralampio, José M. Martínez, and Enrique Sánchez Marcos*
}

Cite This: Inorg. Chem. 2021, 60, 13578-13587

Read Online

ABSTRACT: The physicochemical properties of the three heaviest alkaline-earth cations, $\mathrm{Sr}^{2+}, \mathrm{Ba}^{2+}$, and $\mathrm{Ra}^{2+}$ in water have been studied by means of classical molecular dynamics (MD) simulations. A specific set of cation-water intermolecular potentials based on $a b$ initio potential energy surfaces has been built on the basis of the hydrated ion concept. The polarizable and flexible model of water MCDHO2 was adopted. The theoreticalexperimental comparison of structural, dynamical, energetic, and spectroscopical properties of $\mathrm{Sr}^{2+}$ and $\mathrm{Ba}^{2+}$ aqueous solutions is satisfactory, which supports the methodology developed. This good

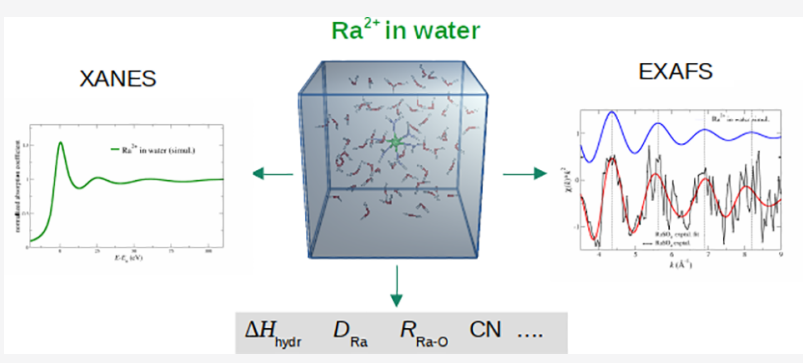
behavior allows a reasonable reliability for the predicted $\mathrm{Ra}^{2+}$ physicochemical data not experimentally determined yet. Simulated extended X-ray absorption fine-structure (EXAFS) and X-ray absorption near-edge spectroscopy spectra have been computed from the snapshots of the MD simulations and compared with the experimental information available for $\mathrm{Sr}^{2+}$ and $\mathrm{Ba}^{2+}$. For the $\mathrm{Ra}^{2+}$ case, the $\mathrm{Ra} \mathrm{L}_{3}$-edge EXAFS spectrum is proposed. Structural and dynamical properties of the aqua ions for the three cations have been obtained and analyzed. Along the $\left[\mathrm{M}\left(\mathrm{H}_{2} \mathrm{O}\right)_{n}\right]^{m+}$ series, the $\mathrm{M}-\mathrm{O}$ distance for the first-hydration shell is $2.57,2.81$, and 2.93 $\AA$ for $\mathrm{Sr}^{2+}, \mathrm{Ba}^{2+}$, and $\mathrm{Ra}^{2+}$, respectively. The hydration number also increases when one is going down along the group: 8.1, 9.4, and 9.8 for $\mathrm{Sr}^{2+}, \mathrm{Ba}^{2+}$, and $\mathrm{Ra}^{2+}$, respectively. Whereas $\left[\mathrm{Sr}\left(\mathrm{H}_{2} \mathrm{O}\right)_{8}\right]^{2+}$ is a typical aqua ion with a well-defined structure, the $\mathrm{Ba}^{2+}$ and $\mathrm{Ra}^{2+}$ hydration provides a picture exhibiting an average between the ennea- and the deca-hydration. These results show a similar chemical behavior of $\mathrm{Ba}^{2+}$ and $\mathrm{Ra}^{2+}$ aqueous solutions and support experimental studies on the removal of Ra-226 of aquifers by different techniques, where $\mathrm{Ra}^{2+}$ is replaced by $\mathrm{Ba}^{2+}$. A comparison of the heavy alkaline ions, $\mathrm{Rb}^{+}$and $\mathrm{Cs}^{+}$, with the heavy alkaline-earth ions is made.

\section{INTRODUCTION}

The solution chemistry of alkaline-earth cations is extremely wide, being involved in a huge number of domains of chemistry, biology, geology, and chemical engineering. ${ }^{1-3}$ Whereas the lighter alkaline-earth cations, particularly, $\mathrm{Mg}^{2+}$ and $\mathrm{Ca}^{2+}$, are ubiquitous in many systems and natural environments, having been deeply studied by experimental and theoretical techniques, their heavy alkaline-earth group companions are much less disseminated and their solution chemistry is more limited, particularly that of $\mathrm{Ra}^{2+}$. The mitic radium discovery by Marie and Pierre Curie opened the field of the nuclear chemistry, ${ }^{4}$ but both its extremely low abundance in nature and its very high radioactivity that makes its experimental handling hazardous have limited its data compilation. Thus, there are not experimental studies providing the hydration number nor the average $\mathrm{Ra}-\mathrm{O}\left(\mathrm{H}_{2} \mathrm{O}\right)$ distance of the aqua ion. These shortcomings stimulate the use of theoretical tools to undertake the estimation of physicochemical properties hardly accessible by experiments. ${ }^{5,6}$ The problem arising from this strategy is to evaluate the degree of confidence of these theoretical results if experimental results are not available for comparison. Two precedent alkaline-earth cations, $\mathrm{Sr}^{2+}$ and $\mathrm{Ba}^{2+}$, are good candidates to be investigated together with $\mathrm{Ra}^{2+}$ in order to analyze the evolution of properties along the group in a systematic way, starting from a regular increase of the ionic radius. Luckily, for these two ions, there is enough experimental chemical information to validate the theoretical results.

There are several works about the structural properties of the $\mathrm{Sr}^{2+}$ aqua ion. By means of extended X-ray absorption fine structure (EXAFS) studies, ${ }^{7-13}$ coordination numbers between 7.3 and 10.3 have been proposed, 8 being the most usual value. $^{9,11,14,15}$ A small range of $\mathrm{Sr}-\mathrm{O}$ distances, between 2.57 and $2.64 \AA$ was found. By means of classical molecular dynamics $(\mathrm{MD}){ }^{14-18}$ coordinations of $\sim 8$ have been found with $\mathrm{Sr}-\mathrm{O}$ distances in the range $2.5-2.7 \AA$. In a quantum mechanics/molecular mechanics (QM/MM) study, ${ }^{19}$ a

Received: June 22, 2021

Published: August 13, 2021 
Table 1. Interaction Energies and $\mathrm{M}-\mathrm{O}$ Distances of $\mathrm{Sr}^{2+}, \mathrm{Ba}^{2+}$, and $\mathrm{Ra}^{2+} \mathrm{Hydrates}^{a}$

\begin{tabular}{|c|c|c|c|c|c|}
\hline \multirow[b]{2}{*}{ structure } & \multicolumn{3}{|c|}{$E_{\text {int }}(\mathrm{kcal} / \mathrm{mol})$} & \multicolumn{2}{|c|}{$R_{\mathrm{M}-\mathrm{O}}(\AA)$} \\
\hline & $\mathrm{QM} / / \mathrm{QM}$ & pot//QM & pot//pot & $R_{\mathrm{QM}}$ & $R_{\text {Pot }}$ \\
\hline $\mathrm{Sr}\left(\mathrm{H}_{2} \mathrm{O}\right)_{7}^{2+}$ & -251.3 & -254.6 & -256.5 & 2.56 & 2.55 \\
\hline $\mathrm{Sr}\left(\mathrm{H}_{2} \mathrm{O}\right)_{8}{ }^{2+}$ & -272.5 & -272.4 & -274.8 & 2.59 & 2.59 \\
\hline $\mathrm{Sr}\left(\mathrm{H}_{2} \mathrm{O}\right)_{8}{ }^{2+}\left(\mathrm{H}_{2} \mathrm{O}\right)$ & -292.6 & -288.8 & -292.5 & $8 \times 2.59 / 1 \times 4.52$ & $8 \times 2.59 / 1 \times 4.43$ \\
\hline $\mathrm{Sr}\left(\mathrm{H}_{2} \mathrm{O}\right)_{9}{ }^{2+}$ & -288.6 & -284.1 & -288.2 & 2.62 & 2.64 \\
\hline $\mathrm{Ba}\left(\mathrm{H}_{2} \mathrm{O}\right)_{8}^{2+}$ & -241.2 & -241.1 & -247.0 & 2.79 & 2.77 \\
\hline $\mathrm{Ba}\left(\mathrm{H}_{2} \mathrm{O}\right)_{8}^{2+}\left(\mathrm{H}_{2} \mathrm{O}\right)$ & -260.9 & -258.9 & -264.2 & $8 \times 2.79 / 1 \times 4.70$ & $8 \times 2.79 / 1 \times 4.59$ \\
\hline $\mathrm{Ba}\left(\mathrm{H}_{2} \mathrm{O}\right)_{9}^{2+}$ & -258.0 & -257.0 & -263.2 & 2.82 & 2.82 \\
\hline $\mathrm{Ra}\left(\mathrm{H}_{2} \mathrm{O}\right)_{8}^{2+}$ & -215.4 & -214.2 & -225.2 & 2.91 & 2.90 \\
\hline $\mathrm{Ra}\left(\mathrm{H}_{2} \mathrm{O}\right)_{9}{ }^{2+}$ & -236.6 & -235.1 & -241.6 & 2.99 & 2.94 \\
\hline $\mathrm{Ra}\left(\mathrm{H}_{2} \mathrm{O}\right)_{10}^{2+}$ & -255.1 & -253.0 & -256.8 & 2.96 & 2.98 \\
\hline
\end{tabular}

${ }^{a_{T}}$ The following notation is used: "calculation level employed//origin of the geometry used".

coordination number of 9 with the peak distance at $2.69 \AA$ was reported. Data are collected in Table 2.

There are several experimental studies about $\mathrm{Ba}^{2+}$ hydration, which are collected in Table 2. Persson et al. ${ }^{9}$ determined a coordination number of 8 with an interatomic $\mathrm{Ba}-\mathrm{O}$ distance of $2.82 \AA$ by large-angle X-ray scattering-EXAFS. Recently, Migliorati et $\mathrm{al}^{20}$ have studied $\mathrm{Ba}^{2+}$ hydration by EXAFS spectroscopy and computer simulations. Their EXAFS fit found a $\mathrm{Ba}-\mathrm{O}$ distance of $2.85 \AA$ and a hydration number of 8 . MD studies ${ }^{14,18,20,21}$ using rigid water models obtained the first-shell coordination numbers between 8 and 8.8 with peak distances in the $2.75-2.85 \AA$ range. Hofer et al. ${ }^{22}$ obtained a first-shell coordination number of 9.3 with the peak distance at $2.86 \AA$ and a second shell formed by $\sim 24$ water molecules by means of a $\mathrm{QM} / \mathrm{MM}$ study. The later results are in contrast with those derived from an ab initio MD study of Rempe's group, ${ }^{23}$ where an octa-coordination was found at $2.8 \AA$.

There are two quantum mechanical studies on the formation of $\mathrm{Ra}^{2+}$ hydrated clusters, ${ }^{5,24}$ and only one theoretical work devoted to study its hydration in aqueous solution ${ }^{6}$ by means of the fragment molecular orbital-MD technique. A first-shell coordination number of 8.1 was predicted with a peak distance of $2.85 \AA$. No experimental characterization of the radium aqua ion has been found in the literature, but an experimental $\mathrm{Ra}-\mathrm{O}$ distance has been determined by EXAFS by Hedström et al. ${ }^{25}$ for the radium sulfate crystal.

This work aims to carry out a systematic theoretical study on the hydration of the three heaviest alkaline-earth cations. The $\mathrm{MD}$ simulations of the three cations in water were performed on the same methodological basis so that the difference found must be a consequence of the intrinsic physicochemical properties of the ions. The comparison of theoretical and experimental results, mainly for $\mathrm{Sr}^{2+}$ and $\mathrm{Ba}^{2+}$, will assess our methodology and, on the basis of good agreement, support the physicochemical properties found for $\mathrm{Ra}^{2+}$ in aqueous solution.

\section{METHODS}

This section has been split into three parts, the first of them being devoted to the building of the cation-water intermolecular potentials based on the hydrated ion model proposed by our group. ${ }^{26-28}$ The second part gives the QM and MD computational details. The third one describes the procedure to simulate the X-ray absorption spectra.

Interaction Potentials. The basic idea of the hydrated ion model is the recognition that the representative species interacting in aqueous solution is the charged metal cation surrounded by a given number of water molecules. ${ }^{1}$ Then, our original statistical implementation of the concept was based on the development of a hydrated ion-water interaction potential $\left(\left[\mathrm{M}\left(\mathrm{H}_{2} \mathrm{O}\right)_{n}\right]^{m+}-\mathrm{H}_{2} \mathrm{O}\right)$ for stable aqua ions based on first-principles. ${ }^{26,28}$ The consideration of the $\left[\mathrm{M}\left(\mathrm{H}_{2} \mathrm{O}\right)_{n}\right]^{m+}$ aggregate as the key entity to deal with intermolecular interactions is a natural way to include many-body effects in an effective pairwise potential. Later on, a second potential was built to describe the intrinsic aqua ion dynamics, that is, the ionwater first-shell (IW1) interaction ${ }^{27,28}\left(\left[\mathrm{M}-\left(\mathrm{H}_{2} \mathrm{O}\right)_{n}\right]^{m+}\right)$. These potentials have been applied to a set of stable monoatomic ${ }^{28-31}$ and molecular ${ }^{32,33}$ aqua ions, and we refer to these studies for further details. Aqua ions' stability ranges from few hundreds of years for $\left[\operatorname{Ir}\left(\mathrm{H}_{2} \mathrm{O}\right)_{6}\right]^{3+}$ to about few picoseconds for several lanthanoid and heavy alkaline aqua ions. ${ }^{34}$ Our model was only valid when the time of first-shell water release is longer than the simulation time. Otherwise, there would be "first-shell" water molecules in the bulk during the simulation time. To overcome this shortcoming in the methodology, an improvement was added considering that there are not two types of water molecules in the simulation, but water molecules are sensitive to the local environment by means of a polarizable and flexible potential, the mobile charge density harmonic oscillator (MCDHO), which is a shell model. ${ }^{35}$ This exchangeable hydrated ion model has been already applied to the description of aqueous solutions of trivalent lanthanoid and actinoid cations. ${ }^{36-40}$ In the present study, we have chosen the MCDHO2 potential, ${ }^{41}$ a revised MCDHO version which improves the water mobility description, as already proven for the demanding cases of the heavy alkaline $\mathrm{Rb}(\mathrm{I})$ and $\mathrm{Cs}(\mathrm{I}) .{ }^{42}$ Details on the functional form and the potential construction are given in Supporting Information.

Figure S2 of Supporting Information displays some representative structures used to build the intermolecular potentials. About 470 structures were used for each of the $\mathrm{Sr}^{2+}-\mathrm{H}_{2} \mathrm{O}$ and $\mathrm{Ba}^{2+}-\mathrm{H}_{2} \mathrm{O}$ interaction potential building, whereas only 135 points have been necessary for the $\mathrm{Ra}^{2+}-\mathrm{H}_{2} \mathrm{O}$ case. The $\mathrm{Sr}^{2+}-\mathrm{H}_{2} \mathrm{O}$ potential has been built using hydrates with seven, eight, and nine water molecules, as well as hydrates with up to two water molecules in the second shell. The addition of surface clusters with 7-10 water molecules improved the global behavior of the potential. The $\mathrm{Ba}^{2+}-\mathrm{H}_{2} \mathrm{O}$ potential was built using structures with eight and nine water molecules and up to two water molecules in the second shell. The $\mathrm{Ra}^{2+}-\mathrm{H}_{2} \mathrm{O}$ potential was built using structures with eight and nine water molecules in the first shell and structures with one or two water molecules in the second shell.

Table $\mathrm{S} 2$ in Supporting Information collects the force field parameters for the $\mathrm{Sr}^{2+}-\mathrm{H}_{2} \mathrm{O}, \mathrm{Ba}^{2+}-\mathrm{H}_{2} \mathrm{O}$, and $\mathrm{Ra}^{2+}-\mathrm{H}_{2} \mathrm{O}$ intermolecular potentials. Table 1 shows a set of interaction energies and $\mathrm{M}-\mathrm{O}$ distances for several $\left[\mathrm{M}\left(\mathrm{H}_{2} \mathrm{O}\right)_{n}\right]^{2+}$ clusters computed at the QM level together with the values obtained with the force field (pot). The interaction energy has been calculated as the energy difference between the hydrated cluster energy and the energy, at the minimumenergy geometry, of the isolated fragments, as shown in eq 1

$$
E_{\text {int }}=E_{\left[\mathrm{M}\left(\mathrm{H}_{2} \mathrm{O}\right)_{n}\right]^{m+}}-\left(E_{\mathrm{M}^{m+}}+n E_{\mathrm{H}_{2} \mathrm{O}}\right)
$$

As can be seen, there is a good energy and structural agreement for the most likely coordination numbers in solution. Also, there is a good 
Table 2. Properties of Heavy Alkaline-Earth Cation Aqueous Solution ${ }^{a}$

\begin{tabular}{|c|c|c|c|c|c|c|}
\hline \multirow[b]{2}{*}{ property } & \multicolumn{2}{|r|}{$\mathrm{Sr}^{2+}$} & \multicolumn{2}{|r|}{$\mathrm{Ba}^{2+}$} & \multicolumn{2}{|r|}{$\mathrm{Ra}^{2+}$} \\
\hline & this work & literature & this work & literature & this work & literature \\
\hline$R_{\mathrm{M}-\mathrm{OI}}(\AA)$ & 2.57 & $2.5-2.64^{7-11,13-19,21,61}$ & 2.81 & $2.60-2.86^{9,14,18,20-23,52}$ & 2.93 & $2.85^{6}$ \\
\hline $\mathrm{CN}_{\mathrm{I}}$ & 8.1 & $7.3-10.3^{7-19,61}$ & 9.4 & $7.8-9.3^{9,14,18,20-23,52}$ & 9.8 & $8.1^{6}$ \\
\hline $\mathrm{DW}\left(\AA^{2}\right)$ & 0.017 & $0.0116,{ }^{9} 0.0115,,^{12} 0.021^{13}$ & 0.034 & $0.0112,,^{9} 0.012,,^{52} 0.018^{20}$ & 0.034 & \\
\hline tilt angle ${ }_{\mathrm{I}}(\mathrm{deg})$ & $141(19)$ & $155^{19}$ & $138(38)$ & $155^{22}$ & $135(22)$ & \\
\hline$\epsilon$ (eccentricity) & $0.17(0.08)$ & & $0.22(0.10)$ & & $0.24(0.10)$ & \\
\hline$R_{\mathrm{M}-\mathrm{OII}}(\AA)$ & 4.72 & $4.78-4.85,{ }^{9,61} 4.97,{ }^{19} 4.9^{11}$ & 4.92 & $4.90,^{9} 5^{22}$ & 5.02 & \\
\hline $\mathrm{CN}_{\mathrm{II}}$ & 22 & $19.0-22.7,^{61} 23.5,^{19} 15^{11}$ & 20 & $23.5^{22}$ & 20.9 & \\
\hline tilt angle ${ }_{\mathrm{II}}(\mathrm{deg})$ & $110(38)$ & & $111(20)$ & & $109(38)$ & \\
\hline$\Delta \mu_{\mathrm{I}}(\mathrm{D})$ & $0.2(0.3)$ & & $0.1(0.3)$ & & $0.0(0.3)$ & \\
\hline$\Delta \mu_{\mathrm{II}}(\mathrm{D})$ & $0.0(0.3)$ & & $0.0(0.3)$ & & $0.0(0.3)$ & \\
\hline $\operatorname{MRT}\left(t^{*}=0\right)(\mathrm{ps})$ & $65(4)$ & $\sim 100-1000,{ }^{34,62} 43,,^{14} 182^{18}$ & $38(4)$ & $\sim 100-1000,,^{34,62} 15,,^{14} 148^{18}$ & $20(4)$ & \\
\hline $\operatorname{MRT}\left(t^{*}=2\right)(\mathrm{ps})$ & $90(4)$ & & $53(4)$ & & $29(4)$ & \\
\hline$\tau_{1, \mu} \mu(\mathrm{ps})$ & 44 & & 26 & $8.8^{22}$ & $29(4)$ & \\
\hline$\tau_{2, \mu} \mu(\mathrm{ps})$ & 8 & & 4 & $3.1^{22}$ & 4 & \\
\hline$\Delta H_{\text {hyd }}(\mathrm{kcal} / \mathrm{mol})$ & $-353(15)$ & $-351.3,^{2}-344.9^{9}$ & $-322(12)$ & $-318.4^{2},-311.9,^{9}-300^{21}$ & $-302(21)$ & $-315.7^{2},-302.6^{9}$ \\
\hline$D\left(10^{-5} \mathrm{~cm}^{2} / \mathrm{s}\right)$ & $0.6(0.2)$ & $0.79,^{2} 0.72,^{16} 0.66^{18}$ & $0.8(0.1)$ & $0.847,,^{2} 0.9,{ }^{14} 0.64^{18}$ & $0.9(0.1)$ & $0.89^{2}$ \\
\hline
\end{tabular}

energy reproduction of the whole set of structures included in the fitting as shown in Figures S3-S5 of Supporting Information, with standard deviations of $3.5,2.7$, and $3.7 \mathrm{kcal} / \mathrm{mol}$, for $\mathrm{Sr}^{2+}, \mathrm{Ba}^{2+}$, and $\mathrm{Ra}^{2+}$, respectively.

MD and QM Computational Details. MD simulations in the canonical ensemble $(N V T)$ at $300 \mathrm{~K}$ were carried out using an inhouse modification of the DL_POLY program ${ }^{43}$ (classic version), which allows the use of the $\mathrm{MCDHO} 2$ potential. A fictitious mass of 0.1 a.u. is associated with the mobile charges of the cations and water oxygen in order to solve the atomic and molecular charge distribution by propagating these fictitious masses together with the rest of real particles. Simulation box contained 1 metal cation and 1000 water molecules, with a box length that fits the experimental water density at this temperature $\left(0.997 \mathrm{~g} / \mathrm{cm}^{3}\right)$. Also, $1 \mathrm{~ns}$ was produced for each cation with a time step of $0.1 \mathrm{fs}$. Long-range interactions were treated by means of the Ewald sum with a cutoff radius of $14 \AA$ and $10^{-6}$ for relative error.

The QM calculations to develop the intermolecular potentials have been performed at the M06-2X/def2-TZVPP level using the effective core pseudopotentials (ECP) of the Stuttgart group: ECP28MDF ${ }^{44}$ for Sr, ECP46MDF ${ }^{44}$ for Ba, and ECP78MDF ${ }^{44}$ for Ra, including 28 , 46 , and 78 electrons, respectively, in the core. The eight valence electrons orbitals are described by the corresponding basis sets associated with the ECPs. The Gaussian $09^{45}$ code was used for the QM calculations.

Simulated X-ray absorption spectroscopy (XAS) Spectra. The simulated spectra were obtained by averaging the computed spectra of snapshots evenly taken from the MD simulation, as previously done by several authors in other metal ion-in-solution studies. ${ }^{46-50}$ To assess the convergence of the simulated XAS spectra with the average number of snapshots, simulated EXAFS spectra with different number of snapshots were computed. A total of 250 snapshots evenly spaced through the $1 \mathrm{~ns}$ trajectories are enough to reach convergence. For each snapshot, the K-edge for $\mathrm{Sr}$, the $\mathrm{L}_{3}$-edge for Ba and Ra, EXAFS, and X-ray absorption near-edge spectroscopy (XANES) spectra were computed by means of the FEFF 9.6 code. ${ }^{51}$ This program calculates ab initio EXAFS and XANES spectra by taking into account multiple scattering effects. Sample input files employed to calculate the simulated spectra are given in Supporting Information (see Figures S6 and S7). The inclusion of hydration shells beyond the first one in the snapshots has no effect on the simulated spectra. This was confirmed by the comparison of two sets of simulated spectra, where the cutoff radius around the metal cation was such that in one case, only the first-shell water molecules were included and in the other case, the second hydration shell was also included. The Hedin-Lundqvist exchange-correlation potential was used to compute the electron density distribution within the selfconsistent field approach. The inner potential correction, $\Delta E_{0}$ was chosen such that the simulated spectrum overlaps the experimental one as much as possible.

Removal of the Multielectron Excitation from Experimental EXAFS Spectra. Experimental EXAFS spectra for $\mathrm{Sr}^{2+}$ and $\mathrm{Ba}^{2+}$ aqueous solutions present multielectron excitations in the region 5-7 $\AA^{-1}{ }^{13,52}$ The identification of multielectron excitations in the EXAFS spectra and their removal is necessary to obtain structural information. Several strategies have been suggested for this purpose. ${ }^{53-56}$ We have adopted the procedure proposed by Ohta et al., 57 which was successfully applied in a previous work $^{42}$ to the EXAFS signals of $\mathrm{Rb}^{+}$and $\mathrm{Cs}^{+}$. We refer to this paper for further details.

\section{RESULTS AND DISCUSSION}

Table 2 collects structural and dynamical properties of the three heavy alkaline-earth cations in water derived from the analysis of the MD simulations. Experimental and theoretical data reported by previous studies have also been included in the table. It must be noted that for $\mathrm{Ra}^{2+}$, the available information is very scarce. A global prospect of the results obtained in this study shows that our results are in general within the wide range of the values proposed by precedent studies. The reason of such a wide range is, at least partially, due to the fact that there are a large number of different techniques included in the data collection.

The first illustrative property assessing the classical force field employed in the simulation is the hydration energy. The calculated hydration enthalpy follows the experimental trend, ${ }^{2}$ $\left|\Delta H_{\text {hydr }}\left(\mathrm{Sr}^{2+}\right)\right|>\left|\Delta H_{\text {hydr }}\left(\mathrm{Ba}^{2+}\right)\right| \approx\left|\Delta H_{\text {hydr }}\left(\mathrm{Ra}^{2+}\right)\right|$, and the worst estimation only deviates $4 \%$ from the experimental value. Interestingly, Persson et al. ${ }^{9}$ examined the experimental hydration enthalpy for the alkaline-earth group, from $\mathrm{Be}^{2+}$ to $\mathrm{Ba}^{2+}$, and found a reasonable linear correlation with the inverse of the $\mathrm{M}-\mathrm{O}$ distance. Their values for $\mathrm{Sr}^{2+}(-344.9 \mathrm{kcal} / \mathrm{mol})$ and $\mathrm{Ba}^{2+}(-311.9 \mathrm{kcal} / \mathrm{mol})$ are almost the same values obtained in this work considering the uncertainties: $-353 \pm 15$ and $-322 \pm 12 \mathrm{kcal} / \mathrm{mol}$ for $\mathrm{Sr}^{2+}$ and $\mathrm{Ba}^{2+}$, respectively. Their extrapolated hydration enthalpy for $\mathrm{Ra}^{2+}$ is $-302.6 \mathrm{kcal} / \mathrm{mol}$, the same value predicted by us (see Table 2). Bearing in mind 
the uncertainties associated with our estimation and the model employed by Persson et al., this perfect match must be regarded with caution. Nevertheless, the result reinforces the coherence of the hydration energies derived from the use of the new potentials. The sequence qualitatively follows the size of the hydrated ion, what can be roughly estimated by the first minimum in the $\mathrm{M}-\mathrm{H}$ radial distribution functions (RDFs): $3.97,4.27$, and $4.30 \AA$ for $\mathrm{Sr}^{2+}, \mathrm{Ba}^{2+}$, and $\mathrm{Ra}^{2+}$, respectively. When dealing with small cations, it has long been recognized that their hydration energies can be roughly split into two contributions. The first one is due to the specific interactions of the first-shell water molecules with the central cation and among them. The second contribution is due to the interactions of the hydrated ion with the bulk represented by a polarizable dielectric continuum, which is a generalization of the Born term. This strategy ${ }^{58-60}$ known as the semicontinuum solvation model is an operative way to supply a generally well-balanced description of the energetics of the solvation phenomenon. In our particular case, the aqua ion size is a good structural parameter to estimate the $\Delta H_{\text {hydr }}$ sequence of these heavy alkaline-earth cations. The discrete contribution is dominated by the direct interaction of the first-shell water molecules with the cations whose charge is the same for all of them. The closer the water molecules are to the cation, the stronger the interaction. The minimum of $M-H_{I} R D F$ is a parameter featuring this fact. The sequence of this contribution is also reflected in Table 1 , where the interaction energies both from QM calculations and the developed potentials favor $\mathrm{Sr}^{2+}$ versus $\mathrm{Ba}^{2+}$ and $\mathrm{Ra}^{2+}$ aqua ions. For aqua ions with the same charge, the continuum contribution is greater when the cavity size is smaller; therefore, the contribution to the $\mathrm{Sr}^{2+}$ hydration will be larger than for $\mathrm{Ba}^{2+}$ and $\mathrm{Ra}^{2+}$.

When comparing with their alkaline partners, $\mathrm{Rb}^{+}$and $\mathrm{Cs}^{+}$, computed at the same level of calculation, ${ }^{42}$ it is observed that their hydration enthalpies are much smaller, -70 and -55 $\mathrm{kcal} / \mathrm{mol}$, respectively. This means between 4.5 and 5 times smaller than those of the heavy alkaline-earth cations. A significant part of this gap is due to the cation charge, that according to the Born term has a quadratic dependence. However, there is also a structural factor associated with the hydrated ion size, which is bigger for the monovalent cations; the first minimum $\mathrm{M}-\mathrm{H}_{\mathrm{I}} \mathrm{RDF}$ appears at 4.4 and $4.7 \AA$, for $\mathrm{Rb}^{+}$and $\mathrm{Cs}^{+}$, respectively. Therefore, the cavity size also contributes to a smaller Born term.

Structural Properties. Figure 1 plots the $\mathrm{M}-\mathrm{O}$ and $\mathrm{M}-\mathrm{H}$ RDFs of the three heavy alkaline-earth divalent cations in water. The first and second hydration shells for $\mathrm{M}-\mathrm{O}$ are well defined, particularly for $\mathrm{Sr}^{2+}$, with a depletion zone between them, indicating the existence of aqua ions in the three cases. Their sizes increase when progressing through the group, as reflected by both the longer $\mathrm{M}-\mathrm{H}_{\mathrm{I}}$ distance when going from $\mathrm{Sr}^{2+}$ to $\mathrm{Ra}^{2+}$, already mentioned above, and the larger coordination number $\left[\mathrm{CN}\left(\mathrm{M}-\mathrm{O}_{\mathrm{I}}\right)=8.1\left(\mathrm{Sr}^{2+}\right), 9.4\left(\mathrm{Ba}^{2+}\right)\right.$, and $\left.9.8\left(\mathrm{Ra}^{2+}\right)\right]$. Regarding the hydration number for $\mathrm{Sr}^{2+}$, there is a general agreement about the eightfold coordination from both experimental results ${ }^{8,9}$ and computer simulations. ${ }^{14}$ First-shell $\mathrm{Sr}-\mathrm{O}$ distances close to our results have also been found in both experimental EXAFS fitting $\left(2.57^{8}\right.$ and $\left.2.63^{9} \AA\right)$ and simulations, $2.58 \AA^{14,15}$ For $\mathrm{Ba}^{2+}$, it is observed that the hydration number derived from most of the experimental studies is a value close to $8,{ }^{9,20}$ whereas statistical simulations predict a wider range of values: $8,{ }^{20} 8.8,{ }^{14}$ and $9.3 .^{22}$ When we examine the simulated EXAFS spectrum, we will come back to

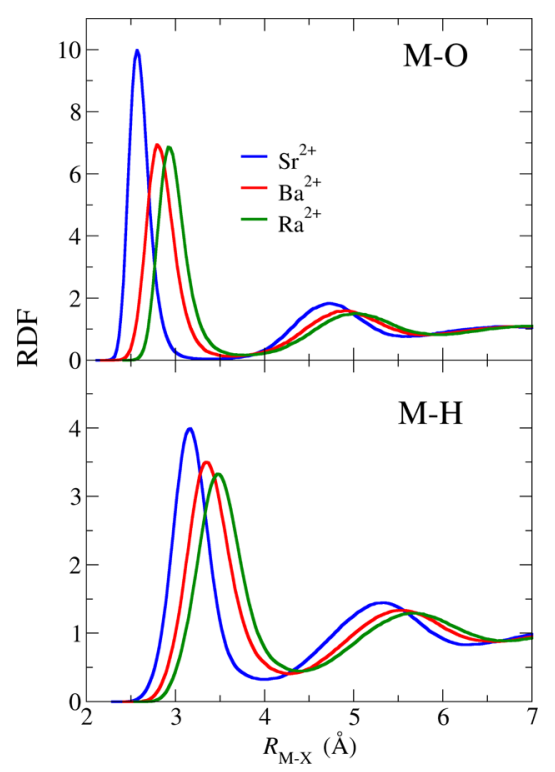

Figure 1. Metal-oxygen (top) and metal-hydrogen radial distribution functions.

this question. The $\mathrm{Ba}-\mathrm{O}$ distance for the first-shell found in this work, $2.81 \AA$, agrees, within the uncertainties, with EXAFS fitting $\left(2.78,{ }^{52} 2.81,{ }^{9} 2.85^{20} \AA\right.$, and X-ray diffraction data, $\left.2.80^{63} \AA\right)$. Likewise, the results from statistical simulations are in the range $2.78^{14}-2.86^{22} \AA$, close values to the distance was found in this work.

A complementary view of the RDF first-peak is the analysis of the $\mathrm{M}-\mathrm{O}$ first peak composition by examining the hydrates distribution of different coordination numbers for the three cations obtained during the simulations. Figure 2 shows the

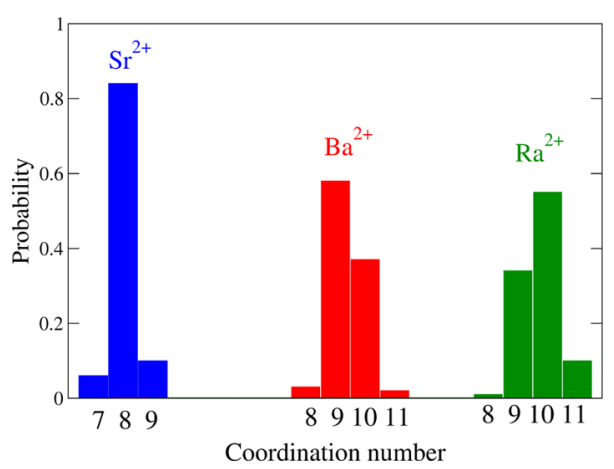

Figure 2. Histogram of the coordination number for the different cation hydrates.

probability of a given hydration number during the simulation. The octahydrate is clearly predominant for the $\mathrm{Sr}^{2+}$ case, whereas for the $\mathrm{Ba}^{2+}$ and $\mathrm{Ra}^{2+}$ ions the distribution is mainly shared between the ennea- and deca-coordinations although with different preferences: the ennea-hydrate is dominant in the $\mathrm{Ba}^{2+}$ case while for $\mathrm{Ra}^{2+}$ is the deca-hydrate. RDFs also reflect the existence of second hydration shells formed in all cases with defined second peaks centered for $\mathrm{M}-\mathrm{O}$ at 4.73 $\left(\mathrm{Sr}^{2+}\right), 4.92\left(\mathrm{Ba}^{2+}\right)$, and $5.03\left(\mathrm{Ra}^{2+}\right) \AA$. Their running integration numbers account for 22-20 water molecules. In the case of the heavy alkaline partners, the second hydration shell is poorly defined for $\mathrm{Rb}^{+}$and absent for $\mathrm{Cs}^{+}, 42$ and there 
is no depletion zone between the first and the second hydration shells for neither of them.

Another parameter representative of the aqua ion consistency is the second cumulant of the first shell ion-oxygen distance defined by means of eq 2

$$
\sigma^{2}\left(\mathrm{M}-\mathrm{O}_{\mathrm{I}}\right)=\left\langle\left(\mathrm{R}\left(\mathrm{M}-\mathrm{O}_{\mathrm{I}}\right)-\overline{\mathrm{R}\left(\mathrm{M}-\mathrm{O}_{\mathrm{I}}\right)}\right)^{2}\right\rangle
$$

a parameter which is associated to the Debye-Waller (DW) factor in spectroscopical and diffraction techniques. The value for the $\mathrm{Sr}^{2+}$ aqua ion is a half of the values found for the other two cations (see Table 2), $\mathrm{Ba}^{2+}$ and $\mathrm{Ra}^{2+}$ having similar values for the DW factors.

Inspection of the $\mathrm{M}-\mathrm{H}$ RDFs leads to an analysis similar to that of the M-O RDFs. The shifting of the first peak of the $\mathrm{M}-\mathrm{H}$ RDF with respect to that of the $\mathrm{M}-\mathrm{O} \mathrm{RDF}$ indicates that on average, water molecules adopt an ion-dipole orientation with respect to the central cation. The tilt angle of the first-shell water molecules is one of the geometrical parameters quantifying this structural feature. The asymptotic value of $180^{\circ}$ means that the water molecule plane contains the cation, that is, the ion-dipole interaction is maximized. The tilt angle does not change too much along the three cases, although it decreases smoothly from $141^{\circ}$ for $\mathrm{Sr}^{2+}$ to $138^{\circ}$ and $135^{\circ}$ for $\mathrm{Ba}^{2+}$ and $\mathrm{Ra}^{2+}$, respectively. These values indicate that theres is a significant cation induced orientation, in spite of thermal effects and water-water interactions. The polarization effects are also reflected in the dipole moment increase experienced by the first-shell water molecules, $0.2 \mathrm{D}$ for $\mathrm{Sr}^{2+}$, $0.1 \mathrm{D}$ for $\mathrm{Ba}^{2+}$, and no change for $\mathrm{Ra}^{2+}$.

An interesting structural parameter representative of the degree of symmetry of the aqua ion is the molecular eccentricity, $\epsilon .^{42}$ This is computed as the average distance between the metal cation and the center of mass of the first hydration shell, as shown by eq 3

$$
\epsilon=\left\langle\left|\vec{r}_{\mathrm{M}^{n+}}-\vec{r}_{\mathrm{CM}}\right|\right\rangle
$$

In the case of a rigid and symmetric aqua ion, the value of $\epsilon$ along the simulation must be 0 . A typical value for the $\mathrm{Li}^{+}$ tetrahydrate, a consistent aqua ion, is $0.2 \AA$, whereas for the $\mathrm{Cs}^{+}$hydrate, which has a poorly structured hydration shell, its value is $0.45 \AA$, the value being $0.37 \AA$ for the intermediate case of the $\mathrm{Rb}^{+}$hydrate. ${ }^{42}$ For the cases of the divalent cations studied here, the $\mathrm{Sr}^{2+}$ octahydrate has a value of $0.17 \AA$, whereas 0.22 and $0.24 \AA$ are the values for the $\mathrm{Ba}^{2+}$ and $\mathrm{Ra}^{2+}$ ennea- and deca-hydrates, respectively.

XAS Spectra. The comparison of the experimental Sr Kedge and $\mathrm{Ba} \mathrm{L}_{3}$-edge $k^{2}$-weighted EXAFS spectra recorded by Persson et al., ${ }^{9}$ for 0.1 and $0.2 \mathrm{M}$ aqueous solutions containing strontium and barium triflate, with the simulated spectra is shown in Figure 3. The experimental EXAFS spectra (black dotted lines) present a multielectron excitation ${ }^{13}$ (MEE) at 6.5 $\AA^{-1}$ for $\mathrm{Sr}$ and at $5.5 \AA^{-1}$ for Ba. To improve the comparison with the simulated spectra, the Ohta et al. methodology ${ }^{57}$ has been used to remove the MEEs. In the process, the spectrum range $[0-10] \AA^{-1}$ has been included for the MEE removal. In order to give a qualitative idea about the MEE impact on the EXAFS spectrum, Figure S8 in Supporting Information plots the MEE contribution to the spectrum, as resulting from the application of Ohta's method for the case of the $\mathrm{Ba}^{2+}$ spectrum. ${ }^{57}$ As expected, the MEE contribution is larger for the heavier $\mathrm{Ba}^{2+}$ cation than for $\mathrm{Sr}^{2+}$ (not shown). As can be seen in Figure 3, there is a good agreement between the simulated EXAFS function (blue lines) and the experimental

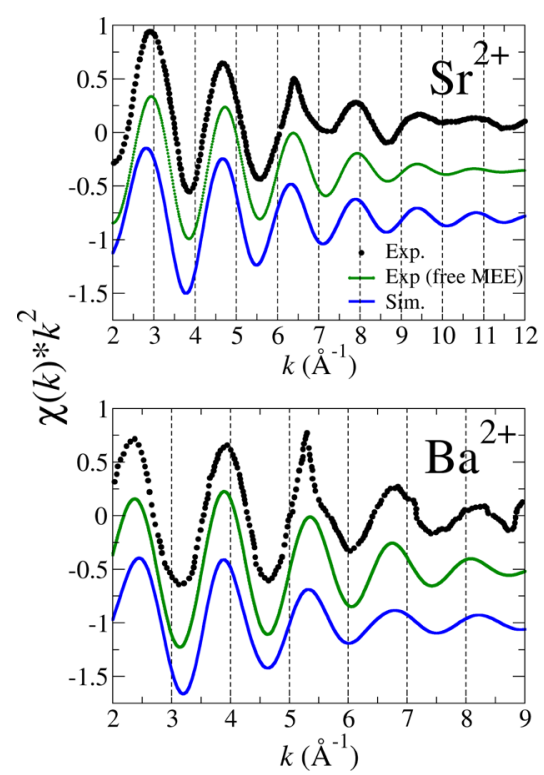

Figure 3. $\mathrm{Sr} \mathrm{K}$-edge and $\mathrm{Ba}_{3}$-edge $k^{2}$-weighted EXAFS spectra of their $\mathrm{Sr}^{2+}$ and $\mathrm{Ba}^{2+}$ aqueous solution: experimental spectra taken from ref 9 (black dots), MEE-removed experimental spectrum (green line), and simulated spectrum (blue line).

ones (green lines), once the MEE has been removed. The simulated EXAFS function has similar frequency and intensity as the experimental ones. The general theoretical-experimental agreement is a strong support for the good behavior of the developed potentials and the structural properties derived from the analysis of the MD simulations. This is also confirmed by the good agreement observed between the experimental ${ }^{9}$ and the simulated XANES spectra for the strontium case (see Figure 4). In their recent study on the $\mathrm{Ba}^{2+}$ hydration,

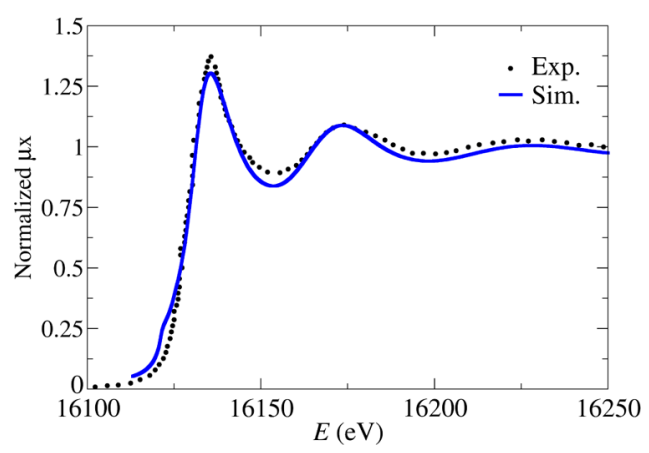

Figure 4. Sr K-edge XANES spectra of a $\mathrm{Sr}^{2+}$ aqueous solution, experimental spectrum taken from ref 9 (black dots) and simulated spectrum (blue line).

Migliorati et al. $^{20}$ have obtained a fairly good agreement between their experimental and simulated EXAFS spectra, with $R_{\mathrm{Ba}-\mathrm{O} \text { (I) }}$ and $R_{\mathrm{Ba}-\mathrm{H}(\mathrm{I})}$ structural parameters close to those found here. (Maxima of $\mathrm{Ba}-\mathrm{O}_{\mathrm{I}}$ and $\mathrm{Ba}-\mathrm{H}_{\mathrm{I}} \mathrm{RDF}$ are 2.78 vs $2.80^{20}$ $\AA$ and 3.35 vs $3.46^{20} \AA$, respectively). The main difference is the coordination number: 9.4 in our case, larger than 8.1 found by D'Angelo's group. Nevertheless, the good theoreticalexperimental agreement obtained by D'Angelo's group as well as by us is justified by the DW-coordination number correlation, as we obtained in our simulation a higher DW factor with a larger coordination number. 
To our knowledge, there is no experimental EXAFS spectrum of a radium salt in water. Based on the good results obtained for the other two heavy alkaline-earth cations, we have simulated the Ra $\mathrm{L}_{3}$-edge $k^{2}$-weighted EXAFS spectrum of a $\mathrm{Ra}^{2+}$ dilute aqueous solution (see blue line in Figure 5). The

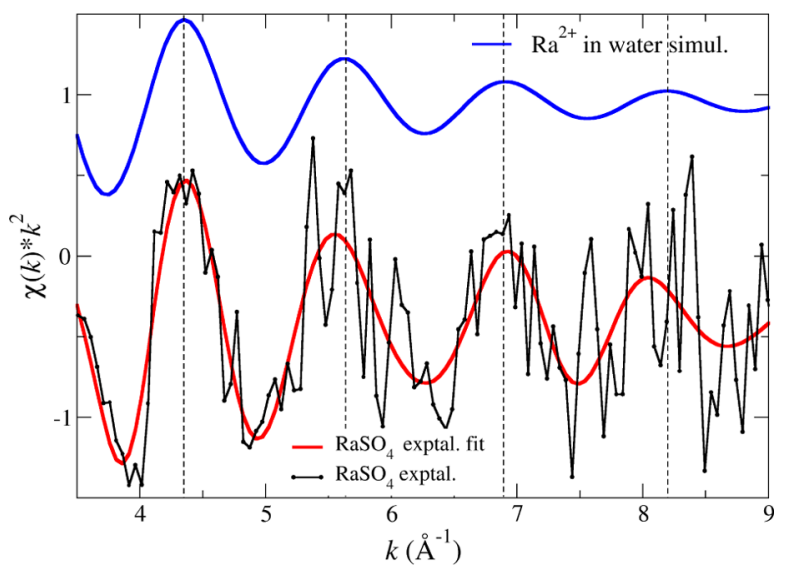

Figure 5. Ra $\mathrm{L}_{3}$-edge $k^{2}$-weighted simulated EXAFS spectrum of a $\mathrm{Ra}^{2+}$ aqueous solution (blue line) and experimental (black line) and fitted (red line) spectrum of a $\mathrm{RaSO}_{4}$ crystalline sample taken from ref 25 .

only EXAFS spectrum of a Ra-containing sample with $\mathrm{Ra}-\mathrm{O}$ backscattering paths has been measured by Hedström et al. ${ }^{25} \mathrm{It}$ corresponds to a solid sample of radium sulfate (black line in Figure 5). The fitting of this spectrum (red line) gives a coordination number of 12 and a $\mathrm{Ra}-\mathrm{O}$ distance of $2.96 \AA$, with a DW factor for this shell of $0.007 \AA^{2}$. The comparison between this experimental fitting and our simulated spectrum of the $\mathrm{Ra}^{2+}$ aqueous solution (blue line) shows a slight higher frequency in the radium sulfate case, a higher intensity, and a slower decaying of the signal at high $k$. All these features are consistent with the structural data obtained from our MD simulation: the $\mathrm{Ra}-\mathrm{O}_{\mathrm{H} 2 \mathrm{O}}, 2.93 \AA$, is shorter than that of $\mathrm{Ra}-$ $\mathrm{O}_{\mathrm{SO} 4}$, the coordination number, 9.8 , is smaller than that of radium sulfate, and the DW factor, $0.034 \AA^{2}$, is larger than that of the solid sample. The similarities and differences between the EXAFS spectra, corresponding to two different, but related samples, seem to suggest that this proposal of EXAFS spectrum for a $\mathrm{Ra}^{2+}$ dilute aqueous solution is sound.

The nonphase-shift-corrected Fourier transforms of the simulated EXAFS spectra of the three cations in water have been plotted in Figure S9 of Supporting Information. As expected, the main peak of the FT is shifted toward higher $R$ values when going from $\mathrm{Sr}^{2+}$ to $\mathrm{Ra}^{2+}$. In the $\mathrm{Ra}^{2+}$ case, the high$R$ region shows an asymmetric shape of the peak, decaying slowly with $R$.

As expected, no experimental XANES spectrum of a $\mathrm{Ra}^{2+}$ aqueous solution has been reported yet. Similarly, as far as we know, no XANES spectrum has been published for $\mathrm{Ba}^{2+}$ containing aqueous solutions. In order to get some experimental reference of a chemically related system to $\mathrm{Ba}^{2+}$ aqueous solution, we have examined the $\mathrm{Ba} \mathrm{L}_{3}$-edge XANES spectrum of the celestite mineral $\left(\mathrm{SrSO}_{4}\right)$ with a very low concentration of $\mathrm{Ba}(\sim 100 \mathrm{ppm})$ substituting $\mathrm{Sr}$, as recorded by Finch et al. ${ }^{64}$ (red points in the top of Figure 6). This supplies a structure of 12 sulfate oxygen atoms surrounding the barium cation. The top of Figure 6 shows the comparison of this experimental spectrum (red dots) and the simulated one

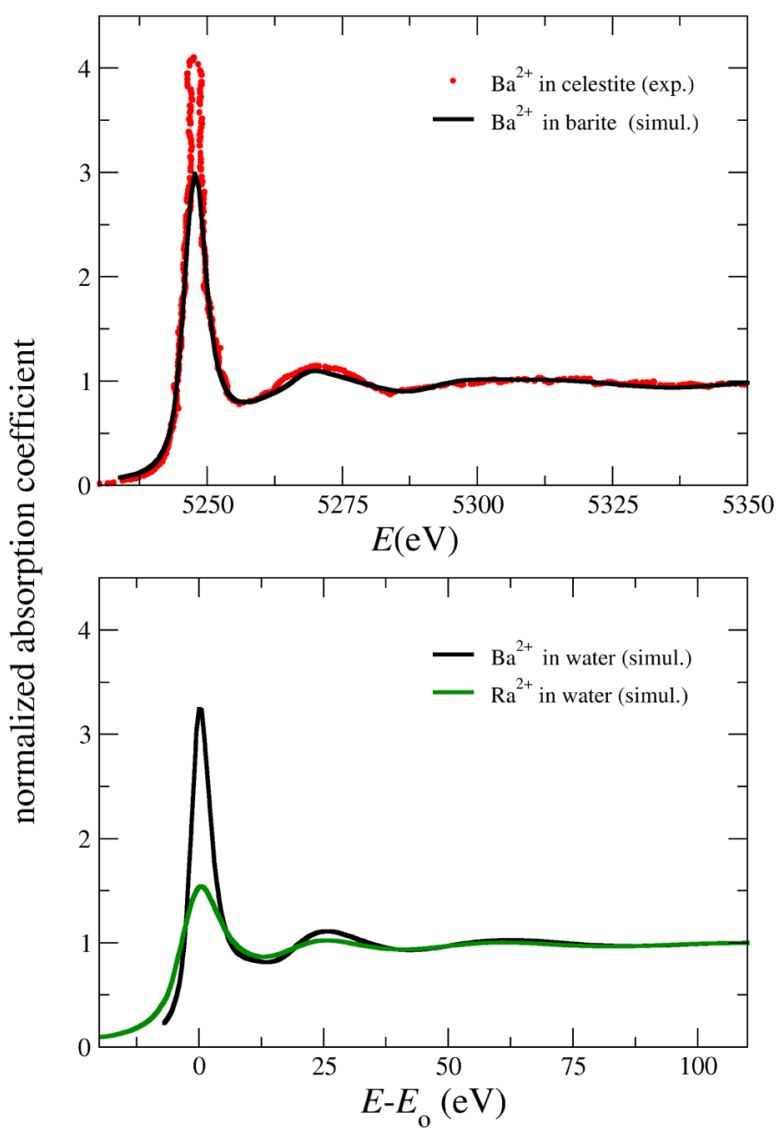

Figure 6. (Top) $\mathrm{Ba}_{3}$-edge XANES spectrum of celestite measured by Finch et al. ${ }^{64}$ and the simulated spectrum taken from the $\mathrm{Ba}^{2+}$ cation and its closest environment from the barite. (Bottom) Ba and $\mathrm{Ra} \mathrm{L}_{3}$-edges XANES simulated spectra of $\mathrm{a} \mathrm{Ba}^{2+}$ and $\mathrm{Ra}^{2+}$ aqueous solution computed from MD snapshots.

(black solid line) performed using the cluster of a $\mathrm{Ba}$ and its closest environment of sulphate anions at the experimental geometry of the isostructural barite mineral. The white line intensity is quite different, but the general shape of both spectra is similar. It must borne in mind that the simulated spectrum was not built with the same structure of the celestite but with a related structure. In any case, results are quite reasonable and give some confidence on the ability of the FEFF code to simulate the XANES spectrum of $\mathrm{Ba}^{2+}$ in water, where the dominant path is also $\mathrm{Ba}-\mathrm{O}$. The average XANES spectrum derived from a set of snapshots of our MD simulations of $\mathrm{Ba}^{2+}$ in water is displayed at the bottom of Figure 6. In the same figure, the $\mathrm{Ra}^{2+} \mathrm{L}_{3}$-edge XANES simulated spectrum of $\mathrm{Ra}^{2+}$ in aqueous solution has also been displayed. It has a shape similar to the corresponding spectrum of $\mathrm{Ba}^{2+}$ in water, although its white line intensity is roughly a half of that of $\mathrm{Ba}^{2+}$. The shape of the $\mathrm{Ba}^{2+}$ spectrum in water is relatively simple, as observed in the case of the $\mathrm{Ba}^{2+}$ in the solid structure of barite (black line in the top of Figure 6).

Dynamical Properties. A set of representative dynamical properties of the three cations in solution have also been collected in Table 2. In addition, the persistence of the different aqua ions as a function of their coordination number has been plotted in Figure 7 and the hydration number evolution around the metal cation as a function of time in Figures S10-S12 of Supporting Information. 


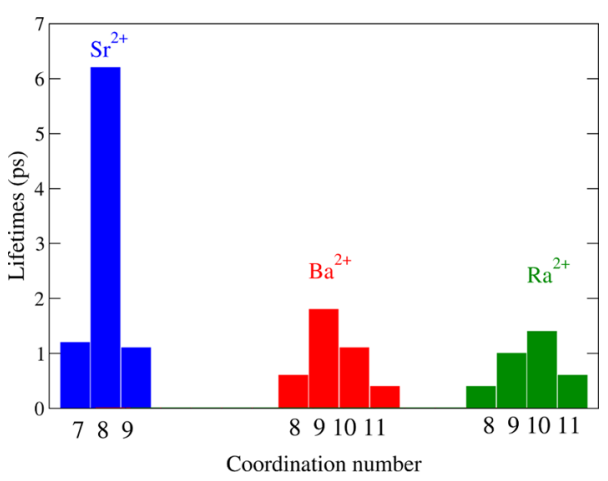

Figure 7. Lifetimes (ps) of different aqua ions for each heavy alkalineearth cation.

Let us start by analyzing the lifetimes of the different aqua ions, a complementary information to that of the distribution of aqua ion coordination number shown in Figure 2. To emphasize this difference between the structural and dynamical information, we have designed the plot showing the time of persistence of each aqua ion of a given coordination number (Figure 7) in a way similar to that adopted for showing the distribution of the coordination number. The joint analysis of both figures clearly shows that the prevalence of a given hydrate does not guarantee a long lifetime. This is particularly clear for the cases of $\mathrm{Ba}^{2+}$ and $\mathrm{Ra}^{2+}$ aqua ions. Although there are several water exchanges for the $\mathrm{Sr}^{2+}$ during the simulation that changes the coordination number (see Figure $S 10$ in Supporting Information), the lifetime of the enneahydrate and heptahydrate are rather short ( $\sim 1 \mathrm{ps})$ compared to that of the octahydrate $(\sim 6 \mathrm{ps})$, as seen in Figure 7 . For $\mathrm{Ba}^{2+}$, the coordination number changes between 9 and 10 with high frequency (Figure S11 of Supporting Information), their lifetimes being short, 2 and 1 ps, respectively. For $\mathrm{Ra}^{2+}$, the coordination number distribution is shifted to the decacoordination (Figure 2), and this aqua ion has the longest, but still short, persistence among the different $\mathrm{Ra}^{2+}$ hydrates.

The dynamical behavior of the aqua ions can be also quantified by the mean residence times (MRTs) of water molecules in their first hydration shell. In this way, the values decrease along the group from strontium to radium (see Table 2). For $t^{*}=0,2 \mathrm{ps}$, the values are $65,90 \mathrm{ps}, 38,53 \mathrm{ps}$, and 20 , $29 \mathrm{ps}$ for $\mathrm{Sr}^{2+}, \mathrm{Ba}^{2+}$, and $\mathrm{Ra}^{2+}$, respectively. If one bears in mind that for pure water, the $\mathrm{MCDHO} 2$ potential gives a value of $2.2 \mathrm{ps}$ for the persistence of a water molecule in the hydration shell of another water molecule, one must recognize the ability of the divalent cation to slow down the dynamical effects of water molecules in its closest environment. This is reinforced by the analysis of their heavy alkaline partners, $\mathrm{Rb}^{+}$and $\mathrm{Cs}^{+}$, for whose first hydration shells, the MRTs of water molecules are in the order of 6-11 ps. ${ }^{42}$ The comparison of the dynamical properties for the three heavy alkaline-earth cations shows how the $\mathrm{Sr}^{2+}$ octahydrate is also the least labile aqua ion from the dynamical view.

The cation self-diffusion coefficient (see Table 2) follows the experimental ${ }^{2}$ trend, increasing along the group. The higher stability of the $\mathrm{Sr}^{2+}$ octahydrate and its smaller size favors a strong interaction with the second hydration shell, which hampers the mobility of the rather rigid hydrated ion. The larger size of the heavier $\mathrm{Ba}^{2+}$ and $\mathrm{Ra}^{2+}$ and their more labile structures reduce the interaction with the second hydration, such as a higher cation mobility is permitted. This trend is also confirmed when analyzing the mobility of the monovalent heavy alkaline $\mathrm{Rb}^{+}$and $\mathrm{Cs}^{+}$. Their diffusion coefficients are $\sim 1.2 \times 10^{-5} \mathrm{~cm}^{2} \mathrm{~s}^{-1}$ values higher than those of the alkalineearth cations studied $\left(0.6-0.9 \times 10^{-5} \mathrm{~cm}^{2} \mathrm{~s}^{-1}\right)$.

The reorientational dynamics of the first-shell water molecules is similar for $\mathrm{Ba}^{2+}$ and $\mathrm{Ra}^{2+}$ aqua ions and is slower for those water molecules surrounding $\mathrm{Sr}^{2+}$. Table S3 in Supporting Information collects the values for the first- $(i=1)$ and second-order $(i=2)$ reorientational times around the dipole moment $\left(\tau_{i, \mu}\right)$, the $\mathrm{H}-\mathrm{H}$ and $\mathrm{O}-\mathrm{H}$ axis $\left(\tau_{i, \mathrm{H}-\mathrm{H}} ; \tau_{i, \mathrm{O}-\mathrm{H}}\right)$, and the normal direction to the molecular plane $\left(\tau_{i,} \perp\right)$. These results correlate well with the previous dynamical discussion. For all the ions, the dynamics of the first-shell water molecules is slower than in bulk water. The intrinsic dynamics of water molecules forming the first hydration shell is more restricted in their orientational mobility around the cation for the $\mathrm{Sr}^{2+}$ case, which once more confirms the stability of its aqua ion. The orientational dynamics of the $\mathrm{Ba}^{2+}$ and $\mathrm{Ra}^{2+}$ water molecules is similar and points out the more labile character of their hydrates.

\section{CONCLUDING REMARKS}

The behavior of the intermolecular potentials developed to describe the hydration of the heaviest alkaline-earth cations in water by classical MD simulations has been shown to be satisfactory. Energy, structural, dynamical, and spectroscopical properties derived from the analysis of the statistical trajectories are in reasonable agreement with the available experimental information. The scarce information on $\mathrm{Ra}^{2+}$ hydration makes the assessment about this cation more difficult, but the good results for the other two cations are a convincing support as the three cations were treated on the same methodological foot to derive their intermolecular potentials. Likewise, indirect comparisons with chemically related samples gives confidence of the predicted theoretical results. The good behavior of the $\mathrm{Ra}^{2+}$ potential offers an additional route toward the computation of a wide range of thermodynamic properties of solutions containing its hydrated ions at moderate computational efforts using classical MD simulations. This could help to provide a new view on the often contradicting results found in the literature. The comparison of the results obtained provides a picture, where the $\mathrm{Ba}^{2+}$ and $\mathrm{Ra}^{2+}$ cations show similar hydration properties. Their hydrates exhibit a significant flexibility and ability to change their large hydration shells; thus, we may consider that the $\mathrm{Sr}^{2+}$ aqua ion behavior differs from theirs because it appears like a more stable and consistent hydrated complex, that is a stable aqua ion. The comparison between the heavy alkaline-earth and alkaline cations leads to conclude that for the former ions, the ion-solvent interactions are dominant with respect to the solvent-solvent ones. This determines their structural and dynamical properties: $\mathrm{Ba}^{2+}$ and $\mathrm{Ra}^{2+}$ are mild aqua ions.

On the basis of the results obtained here, $\mathrm{Ba}^{2+}$ is a good candidate to substitute $\mathrm{Ra}^{2+}$ in experimental efforts devoted to get insights into the control mechanisms of $\mathrm{Ra}^{2+}$ release from the nuclear waste into aquifers and further related processes. $^{65,66}$

\section{ASSOCIATED CONTENT}

\section{SI Supporting Information}

The Supporting Information is available free of charge at https://pubs.acs.org/doi/10.1021/acs.inorgchem.1c01888. 
Parameter force field obtained for $\mathrm{M}^{2+}-\mathrm{H}_{2} \mathrm{O}(\mathrm{M}=\mathrm{Sr}$, $\mathrm{Ba}, \mathrm{Ra})$, representative set of structure types employed in the fitted potentials, plots showing the correlation between the QM interaction energies and the predicted values by the developed force field, examples of input FEFF files used for the XAS spectrum simulations, MEE contribution to the Ba EXAFS spectrum, FT modulus of the simulated spectra of $\mathrm{Sr}^{2+}, \mathrm{Ba}^{2+}$, and $\mathrm{Ra}^{2+}$ in water, and the time evolution of the cation first-shell hydration numbers (PDF)

\section{AUTHOR INFORMATION}

Corresponding Author

Enrique Sánchez Marcos - Department of Physical Chemistry, University of Seville, 41012 Seville, Seville, Spain; ○ orcid.org/0000-0002-8367-9105; Phone: +34

955421005; Email: sanchez@us.es

\section{Authors}

Rafael R. Pappalardo - Department of Physical Chemistry, University of Seville, 41012 Seville, Seville, Spain; (1) orcid.org/0000-0003-3751-2395

Daniel Z. Caralampio - Department of Physical Chemistry, University of Seville, 41012 Seville, Seville, Spain

José M. Martínez - Department of Physical Chemistry, University of Seville, 41012 Seville, Seville, Spain; (1) orcid.org/0000-0002-1792-2197

Complete contact information is available at: https://pubs.acs.org/10.1021/acs.inorgchem.1c01888

\section{Notes}

The authors declare no competing financial interest.

\section{ACKNOWLEDGMENTS}

We thank Prof. I. Persson, University of Uppsala, for providing us the experimental EXAFS spectrum of radium sulphate (solid) and strontium and barium triflates in water. This document is the result of the research project (FEDER US1264472) funded by the Junta de Andalucía and University of Sevilla. D.Z.C. thanks the Junta de Andalucía for a postdoctoral fellowship (P11-FQM-7607).

\section{REFERENCES}

(1) Richens, D. T. The Chemistry of Aqua Ions; John Wiley: Chichester, 1997.

(2) Marcus, Y. Ions in Solution and Their Solvation; John Wiley \& Sons: New York, 2015.

(3) Ohtaki, H.; Radnai, T. Structure and dynamics of hydrated ions. Chem. Rev. 1993, 93, 1157-1204.

(4) Curie, P.; Curie, M. Sur une substance nouvelle radio-active, contenu dans la pechblende. Compt. Rendus 1898, 127, 175-178.

(5) Matsuda, A.; Mori, H. Quantum Chemical Study on the Hydration of $\mathrm{Ra}(\mathrm{II})$ : Comparison with the Other Hydrated Divalent Alkaline Earth Metal Ions. J. Comput. Chem., Jpn. 2014, 13, 105-113.

(6) Matsuda, A.; Mori, H. Theoretical Study on the Hydration Structure of Divalent Radium Ion Using Fragment Molecular OrbitalMolecular Dynamics (FMO-MD) Simulation. J. Solution Chem. 2014, 43, 1669-1675.

(7) Pfund, D. M.; Darab, J. G.; Fulton, J. L.; Ma, Y. An XAFS study of Strontium ions and Krypton in supercritical water. J. Phys. Chem. 1994, 98, 13102-13107.

(8) Seward, T. M.; Henderson, C. M. B.; Charnock, J. M.; Driesner, T. An EXAFS study of the solvation and ion pairing in aqueous strontium solution to $300^{\circ} \mathrm{C}$. Geochim. Cosmochim. Acta 1999, 63, 2409-2418.

(9) Persson, I.; Sandström, M.; Yokoyama, H. Structure of the solvated Strontium and Barium ions in aqueous, Dimethyl Sulfoxide and Pyridine solution, and Crystal structure of Strontium and Barium Hydroxide Octahydrate. Z. Naturforsch. 1995, 50, 21-37.

(10) Ramos, S.; Neilson, G. W.; Barnes, A. C.; Capitán, M. J. Anomalous X-ray diffraction studies of $\mathrm{Sr}^{2+}$ hydration in aqueous solution. J. Chem. Phys. 2003, 118, 5542-5546.

(11) Caminiti, R.; Musinu, A.; Paschina, G.; Pinna, G. X-ray diffraction study of aqueous $\mathrm{SrCl}_{2}$ solution. J. Appl. Crystallogr. 1982, $15,482-487$.

(12) Parkman, R. H.; Charnock, J. M.; Livens, F. R.; Vaughan, D. J. A study of the interaction of Strontium ions in aqueous solution with the surface of Calcite and Kaolinite. Geochim. Cosmochim. Acta 1998, 62, 1481-1492.

(13) D’Angelo, P.; Nolting, H.; Pavel, N. V. Evidence for multielectron resonances at the Sr K edge. Phys. Rev. A 1996, 53, $798-805$.

(14) Larentzos, J. P.; Criscenti, L. J. A molecular dynamics study of alkaline earth - chloride complexation in aqueous solution. J. Phys. Chem. B 2008, 112, 14243-14250.

(15) Tofteberg, T.; Öhrn, A.; Karlström, G. Combined quantum chemical statistical mechanical simulations of $\mathrm{Mg}^{2+}, \mathrm{Ca}^{2+}$ and $\mathrm{Sr}^{2+}$ in water. Chem. Phys. Lett. 2006, 429, 436-439.

(16) Deublein, S.; Reiser, S.; Vrabec, J.; Hasse, H. A set of Molecular model for Alkaline-Earth cations in aqueous solution. J. Phys. Chem. B 2012, 116, 5448-5457.

(17) Harris, D. J.; Brodholt, J. P.; Sherman, D. M. Hydration of $\mathrm{Sr}^{2+}$ in hydrothermal solution from ab initio Molecular Dynamics. J. Phys. Chem. B 2003, 107, 9056-9058.

(18) Mamatkulov, M.; Schwierz, N. Force fields for monovalent and divalent metal cations in TIP3P water based on thermodynamic and kinetic properties. J. Chem. Phys. 2018, 148, 074504.

(19) Hofer, T. S.; Randolf, B. R.; Rode, B. M. Sr(II) in water: A labile hydrate with highly mobile structure. J. Phys. Chem. B 2006, 110, 20409-20417.

(20) Migliorati, V.; Caruso, A.; D’Angelo, P. Unraveling the hydration properties of the $\mathrm{Ba}^{2}$ aqua ion: The interplay of Quantum Mechanics, Molecular Dynamics and EXAFS spectroscopy. Inorg. Chem. 2019, 58, 14551-14559.

(21) Raiteri, P.; Demichelis, R.; Gale, J. D. Thermodynamically consistent force field for Molecular Dynamics simulations of AlkalineEarth Carbonates and their aqueous speciation. J. Phys. Chem. C 2015, $119,24447-24458$.

(22) Hofer, T. S.; Rode, B. M.; Randolf, B. R. Structure and dynamics of solvated $\mathrm{Ba}(\mathrm{II})$ in dilute aqueous solution - an ab initio QM/MM MD approach. Chem. Phys. 2005, 312, 81-88.

(23) Chaudhari, M. I.; Soniat, M.; Rempe, S. B. Octa-coordination and the aqueous $\mathrm{Ba}^{2+}$ ion. J. Phys. Chem. B 2015, 119, 8746-8753.

(24) Glendening, E. D.; Feller, D. Dication-Water interaction $\mathrm{M}^{2+}\left(\mathrm{H}_{2} \mathrm{O}\right)_{n}$ clusters for Alkaline Earth metal $\mathrm{M}=\mathrm{Mg}, \mathrm{Ca}, \mathrm{Sr}, \mathrm{Ba}$ and Ra. J. Phys. Chem. 1996, 100, 4790-4797.

(25) Hedström, H.; Persson, I.; Skarnemark, G.; Ekberg, G. Characterization of Radium Sulphate. J. Nucl. Chem. 2013, 940701.

(26) Pappalardo, R. R.; Sánchez Marcos, E. Recovering the concept of the Hydrated Ion for model ionic solutions: A Monte Carlo study of the $\mathrm{Zn}^{2+}$ in water. J. Phys. Chem. 1993, 97, 4500-4504.

(27) Martínez, J. M.; Pappalardo, R. R.; Sánchez Marcos, E. A molecular dynamics study of the $\mathrm{Cr}^{3+}$ hydration based on a fully flexible hydrated ion model. J. Chem. Phys. 1998, 109, 1445-1455.

(28) Martínez, J. M.; Pappalardo, R. R.; Sánchez Marcos, E. Firstprinciples Ion-Water interaction potentials for highly charged monoatomic cations. Computer simulations of $\mathrm{Al}^{3+}, \mathrm{Mg}^{2+}$ and $\mathrm{Be}^{2+}$. J. Am. Chem. Soc. 1999, 121, 3175-3184.

(29) Martínez, J. M.; Torrico, F.; Pappalardo, R. R.; Sánchez Marcos, E. Understanding the Hydration Structure of Square-Planar Aquaions: the $\left[\mathrm{Pd}(\mathrm{H} 2 \mathrm{O})_{4}\right]^{2+}$ Case. J. Phys. Chem. B 2004, 108, 15851-15855. 
(30) Torrico, F.; Pappalardo, R. R.; Sánchez Marcos, E.; Martínez, J. $M$. Hydration structure and dynamic properties of the square planar $\mathrm{Pt}$ (II) aquaion compared to the Pd(II) case. Theor. Chem. Acc. 2006, 115, 196-203.

(31) Carrera, F.; Torrico, F.; Richens, D. T.; Muñoz-Páez, A.; Martínez, J. M.; Pappalardo, R. R.; Sánchez Marcos, E. Combined experimental and theoretical approach to the study of structure and dynamics of the most inert aqua ion $\left[\operatorname{Ir}\left(\mathrm{H}_{2} \mathrm{O}\right)_{6}\right]^{3+}$ in aqueous solution. J. Phys. Chem. B 2007, 111, 8223-8233.

(32) Pérez-Conesa, S.; Torrico, F.; Martínez, J. M.; Pappalardo, R. R.; Sánchez Marcos, E. A Hydrated Ion Model of $\left[\mathrm{UO}_{2}\right]^{2+}$ in Water: Structure, Dynamics, and Spectroscopy from Classical Molecular Dynamics. J. Chem. Phys. 2016, 145, 224502.

(33) Pérez-Conesa, S.; Torrico, F.; Martínez, J. M.; Pappalardo, R. R.; Sánchez Marcos, E. A General Study of Actinyl Hydration by Molecular Dynamics Simulations Using ab initio Force Fields. J. Chem. Phys. 2019, 150, 104504.

(34) Helm, L.; Merbach, A. E. Inorganic and Bioinorganic Solvent Exchange Mechanisms. Chem. Rev. 2005, 105, 1923-1960.

(35) Saint-Martin, H.; Hernández-Cobos, J.; Bernal-Uruchurtu, M. I.; Ortega-Blake, I.; Berendsen, H. J. C. A mobile charge densities in harmonic oscillators (MCDHO) molecular model for numerical simulations: The water-water interaction. J. Chem. Phys. 2000, 113, 10899-10912.

(36) Galbis, E.; Hernández-Cobos, J.; den Auwer, C.; Le Naour, C.; Guillaumont, D.; Simoni, E.; Pappalardo, R. R.; Sánchez Marcos, E. Solving the Hydration Structure of the Heaviest Actinide Aqua Ion Known: The Californium(III) Case. Angew. Chem., Int. Ed. 2010, 49, $3811-3815$.

(37) Galbis, E.; Hernández-Cobos, J.; Pappalardo, R. R.; Sánchez Marcos, E. Collecting high-order interactions in an effective pairwise intermolecular potential using the hydrated ion concept: The hydration of $\mathrm{Cf}^{3+}$. J. Chem. Phys. 2014, 140, 214104.

(38) Morales, N.; Galbis, E.; Martínez, J. M.; Pappalardo, R. R.; Sánchez Marcos, E. Identifying coordination geometries of metal aquaions in water: Application to the case of lanthanoid and actinoid hydrates. J. Phys. Chem. Lett. 2016, 7, 4275-4280.

(39) Pérez-Conesa, S.; Martínez, J. M.; Pappalardo, R. R.; Sánchez Marcos, E. Extracting the Americyl Hydration from an Americium Cationic Mixture in Solution: A Combined X-ray Absorption Spectroscopy and Molecular Dynamics Study. Inorg. Chem. 2018, 57, 8089-8097.

(40) Pappalardo, R. R.; Caralampio, D. Z.; Martínez, J. M.; Sánchez Marcos, E. Hydration Structure of the Elusive Ac(III) Aqua Ion: Interpretation of X-ray Absorption Spectroscopy (XAS) Spectra on the Basis of Molecular Dynamics (MD) Simulations. Inorg. Chem. 2019, 58, 2777-2783.

(41) Villa, A.; Hess, B.; Saint-Martin, H. Dynamics and structure of Ln(III) Aqua Ions: A Comparative Molecular Dynamics study using $\mathrm{ab}$ Initio based flexible and polarizable model potentials. J. Phys. Chem. B 2009, 113, 7270-7281.

(42) Caralampio, D. Z.; Martínez, J. M.; Pappalardo, R. R.; Sánchez Marcos, E. The Hydration Structure of the Heavy-alkalines $\mathrm{Rb}^{+}$and $\mathrm{Cs}^{+}$Through Molecular Dynamics and X-ray Absorption Spectroscopy: Surface Clusters and Eccentricity. Phys. Chem. Chem. Phys. 2017, 19, 28993-29004.

(43) Smith, W.; Forester, T. R.; Todorov, I. T. The DL_POLY Classic; STFC Daresbury Laboratory: Daresbury, 2012.

(44) Lim, I. S.; Stoll, H.; Schwerdtfeger, P. Relativistic small-core energy-consistent pseudopotentials for the alkaline-earth elements from Ca to Ra. J. Chem. Phys. 2006, 124, 034107.

(45) Frisch, M. J.; et al. Gaussian 09, Revision D.01; Gaussian, Inc.: Wallingford, CT, 2009.

(46) Fulton, J. L.; Pfund, D. M.; Wallen, S. L.; Newville, M.; Stern, E. A.; Ma, Y. Rubidium hydration in ambient and supercritical water. J. Chem. Phys. 1996, 105, 2161-2166.

(47) Campbell, L.; Rehr, J. J.; Schenter, G. K.; McCarthy, M. I.; Dixon, D. XAFS Debye-Waller factors in aqueous $\mathrm{Cr}^{3+}$ from Molecular Dynamics. J. Synchrotron Radiat. 1999, 6, 310-312.
(48) Merkling, P. J.; Muñoz-Páez, A.; Sánchez Marcos, E. Exploring the capabilities of X-ray Absorption Spectroscopy for determining the structure of electrolyte solutions: Computed spectra for $\mathrm{Cr}^{3+}$ or $\mathrm{Rh}^{3+}$ in water based on Molecular Dynamics. J. Am. Chem. Soc. 2002, 124, 10911-10920.

(49) Jalilehvand, F.; Spångberg, D.; Lindqvist-Reis, P.; Hermansson, K.; Persson, I.; Sandström, M. Hydration of the calcium ion. An EXAFS, large-angle $\mathrm{x}$-ray scattering, and molecular dynamics simulation study. J. Am. Chem. Soc. 2001, 123, 431-441.

(50) D’Angelo, P.; Barone, V.; Chillemi, G.; Sanna, N.; MeyerKlauche, W.; Pavel, N. V. Hydrogen and Higher Shell Contributions in $\mathrm{Zn}^{2+}, \mathrm{Ni}^{2+}$, and $\mathrm{Co}^{2+}$ Aqueous Solutions: An X-ray Absorption Fine Structure and Molecular Dynamics Study. J. Am. Chem. Soc. 2002, 124, 1958-1967.

(51) Rehr, J. J.; Kas, J. J.; Vila, F. D.; Prange, M. P.; Jorissen, K. Parameter-free calculations of $\mathrm{x}$-ray spectra with FEFF9. Phys. Chem. Chem. Phys. 2010, 12, 5503-5513.

(52) D’Angelo, P.; Pavel, N. V.; Roccatano, D.; Nolting, H. Multielectron excitations at the $\mathrm{L}$ edges of barium in aqueous solution. Phys. Rev. B: Condens. Matter Mater. Phys. 1996, 54, 1212912138 .

(53) Chaboy, J.; Marcelli, A.; Tyson, T. A. Influence of doubleelectron transitions on the EXAFS L edges of rare earth systems. Phys. Rev. B: Condens. Matter Mater. Phys. 1994, 49, 11652-11661.

(54) Solera, J. A.; García, J.; Proietti, M. G. The multielectron excitations at the $\mathrm{L}$ edges in rare-earth ionic aqueous solutions. Phys. Rev. B: Condens. Matter Mater. Phys. 1995, 51, 2678-2686.

(55) Allen, P. G.; Bucher, J. J.; Shuh, D. K.; Edelstein, N. M.; Craig, I. Coordination chemistry of trivalent Lanthanide and Actinide ions in dilute and concentrated Chloride solutions. Inorg. Chem. 2000, 39, $595-601$.

(56) Anderson, A. J.; Jayanetti, S.; Mayanovic, R. A.; Basset, W. A.; Chou, I.-M. X-ray spectroscopic investigation of fluids in the hydrothermal diamonds anvil cell: The hydration structure of aqueous $\mathrm{La}^{3+}$ up to $300^{\circ} \mathrm{C}$ and 1600 bars. Am. Mineral. 2002, 87, 262-268.

(57) Ohta, A.; Kagi, H.; Tsuno, H.; Nomura, M.; Kawabe, I. Influence of multi-electron excitation on EXAFS spectroscopy of trivalent rare-earth ions and elucidation of change in hydration through the series. Am. Mineral. 2008, 93, 1384-1392.

(58) Claverie, P.; Daudey, J. P.; Langlet, J.; Pullman, B.; Piazzola, D.; Huron, M. J. Studies of Solvent Effects.1. Discrete, Continuum, and Discrete-continuum Models and their Comparison for some Simple Cases $-\mathrm{NH}_{4}{ }^{+}, \mathrm{CH}_{3} \mathrm{OH}$, and Substituted $\mathrm{NH}_{4}{ }^{+}$. J. Phys. Chem. 1978, $82,405-418$.

(59) Sánchez Marcos, E.; Pappalardo, R. R.; Rinaldi, D. Effects of the Solvent Reaction Field on the Geometrical Structures of Hexahydrate Metallic Cations. J. Phys. Chem. 1991, 95, 8928-8932.

(60) Cramer, C. J.; Truhlar, D. G. Implicit Solvation Models: Equilibria, Structure, Spectra and Dynamics. Chem. Rev. 1999, 99, 2161-2200.

(61) Boda, A.; De, S.; Ali, S. M.; Tulishetti, S.; Khan, S.; Singh, J. K. From microhydration to bulk hydration of $\mathrm{Sr} 2+$ metal ion: DFT, MP2 and molecular dynamics study. J. Mol. Liq. 2012, 172, 110-118.

(62) Helm, L.; Merbach, A. E. Water exchange on metal ions: experiments and simulations. Coord. Chem. Rev. 1999, 187, 151-181.

(63) Marques, M. A.; Cabao, M.; de Barros Marques, M.; Gaspar, A. Intermediate-range order in aqueous solutions of salts constituted of divalent ions combined with monovalent counter-ions. J. Phys.: Condens. Matter 2002, 14, 7427-7448.

(64) Finch, A. A.; Allison, N.; Steaggles, H.; Wood, C. V.; Mosselmans, J. F. W. Ba XAFS in Ba-rich standard minerals and the potential for determining Ba structural state in calcium carbonate. Chem. Geol. 2010, 270, 179-185.

(65) Klinkenberg, M.; Weber, J.; Barthel, J.; Vinograd, V.; Poonoosamy, J.; Kruth, M.; Bosbach, D.; Brandt, F. The Solid Solution-aqueous Solution System $(\mathrm{Sr}, \mathrm{Ba}, \mathrm{Ra}) \mathrm{SO}_{4}+\mathrm{H}_{2}$ : a Combined Experimental and Theoretical Study of Phase Equilibria at Sr-rich Compositions. Chem. Geol. 2018, 497, 1-17. 
(66) AlHaddad, N.; Sidaoui, R.; Tabbal, M.; Abbas, I.; Danjou, P.-E.; Cazier-Dennin, F.; Baydoun, R.; Samad, O. E.; Rifai, A. Application of Doehlert experimental design for the removal of radium from aqueous solution by cross-linked phenoxycalix[4] pyrrole-polymer using $\mathrm{Ba}$ (II) as a model. Environ. Sci. Pollut. Res. 2020, 27, 4325-4336. 